\title{
Magnetic Exchange Interactions in a 2D Grid-like Copper(II) Polymer with Bridging End-on Cyanato and Pyrazine Ligands: A DFT Study
}

\author{
Dae-Bok Kang \\ Department of Chemistry, Kyungsung University, Busan 608-736, Korea.E-mail: dbkang@ks.ac.kr \\ Received February 10, 2010, Accepted April 7, 2010
}

\begin{abstract}
The structure of a 2D grid-like copper(II) complex $\left[\mathrm{Cu}(\mathrm{NCO})_{2}\right.$ (pyz)](pyz=pyrazine) (1) consists of $1 \mathrm{D}$ chains of $\mathrm{Cu}$-pyz units connected by double end-on (EO) cyanato bridges. Each $\mathrm{Cu}(\mathrm{II})$ ion has a distorted octahedral coordination, completed by the four EO cyanato and two pyrazine ligands. Magnetic interactions through EO cyanato and pyrazine bridges in $\mathbf{1}$ are discussed on the basis of DFT broken-symmetry calculations at the B3LYP level. For model dicopper(II) complexes I (bridged by cyanato) and II (bridged by pyrazine), electronic structure calculations reproduce very well the experimental couplings for the $\mathrm{S}=1 / 2$ ferromagnetic and antiferromagnetic exchange-coupled 2D system: the calculated exchange parameters $J$ are $+1.25 \mathrm{~cm}^{-1}$ and $-3.07 \mathrm{~cm}^{-1}$ for $\mathbf{I}$ and $\mathbf{I I}$, respectively. The $\sigma$ orbital interactions between the $\mathrm{Cu} x^{2}-y^{2}$ magnetic orbitals and the nitrogen lone-pair orbitals of pyrazine are analyzed from the viewpoint of through-bond interaction. The energy splitting of $0.106 \mathrm{eV}$ between two SOMOs indicates that the superexchange interaction should be antiferromagnetic in II. On the other hand, there are no bridging orbitals that efficiently connect the two copper(II) magnetic orbitals in I because the HOMOs of the basal-apical NCO bridge do not play a role in the formation of overlap interaction pathway. The energy separation in the pair of SOMOs of $\mathbf{I}$ is calculated to be very small $(0.054 \mathrm{eV})$. This result is consistent with the occurrence of weakly ferromagnetic properties in $\mathbf{I}$.
\end{abstract}

Key Words: Molecular magnetism, Density functional theory, Superexchange interaction

\section{Introduction}

During the past decades, spectacular advances have been made in the research of molecule-based magnetic materials due to their impressive structural diversity and potential applications. ${ }^{1}$

An essential approach to provide molecule-based magnets is to construct ordered extended structures with superexchange interactions between the metal centers. ${ }^{2}$ In relation to the ligands for the preparation of those materials, potential bridging ligands such as pseudohalide and pyrazine provide efficient superexchange pathways.

Pseudohalides $\left(\mathrm{N}_{3}^{-}, \mathrm{OCN}^{-}, \mathrm{SCN}^{-}\right.$, etc. $)$are the versatile ligands which can coordinate to transition metal ions in different ways, for example as a bridge or as a terminal ligand. Such a coordination versatility has not only resulted in a variety of crystal structures of zero, one, two, and three dimensions, but also the tuning of magnetic properties of these compounds by adjusting the relative positions of metal atoms and their exchange coupling parameters $J$. Among these, azide has been undoubtedly one of the most interesting magnetic coupling species found so far in molecular magnetism. ${ }^{3}$ On the contrary, the ability of the cyanate to facilitate magnetic exchange has only been scarcely studied. ${ }^{4}$ The cyanate anion, like the most widely studied azide, can act as a bridging ligand between metal atoms. It shows preference for the end-on (EO) bridging mode through the nitrogen atom. In this kind of bridging, the cyanato ligand has been shown to be able to mediate ferromagnetic interactions. ${ }^{4}$

An efficient way for the generation of magnetic interactions between metallic centers concerns the use of pyrazine ligands. Pyrazine (pyz) is a classical bridging ligand that has been ex- tensively used in the design of novel network structures and shown to stabilize magnetic ordering in molecule-based systems. This ligand coordinates to metal ions in a bis-monodentate fashion through its two nitrogen lone pairs leading to intramolecular metal-metal separations of about 6.8 - $7.5 \AA$, assembling one-dimensional (1D) linear chains or two-dimensional (2D) layer compounds. ${ }^{5}$ The most extensively studied complexes of this type have been copper(II), where it has been found that an important factor in determining the nature of the exchange interactions is an effective overlap of $d$ (metal)- $\sigma$ (pyz) orbitals. ${ }^{6}$ Overall, the interaction through this ligand is weak. Nevertheless, many systems using pyrazine (or its derivatives) as a building block display antiferromagnetic ordering ranging from a few Kelvin up to $62 \mathrm{~K}^{7}$

In this work we have focused on $\left[\mathrm{Cu}(\mathrm{NCO})_{2}(\right.$ pyz $\left.)\right]$ that has been characterized as a 2D grid-like polymer by Wriedt et al., ${ }^{8}$ where the thermal variation of its magnetic susceptibility suggests an antiferromagnetic ground state at lower temperatures as well as net ferromagnetic interactions. The magnetic behavior of this compound can be explained by considering the different exchange pathways. Thus, the end-on cyanato bridge promotes a ferromagnetic coupling, while the pyrazine bridge gives rise to antiferromagnetic interactions between copper(II) centers. Theoretical calculations aiming at analyzing the exchange pathways responsible for the weak intramolecular ferro- and antiferromagnetic couplings are presented. Specifically, the focus is directed to the understanding of the magnetic interactions between the paramagnetic metal ions in dimers, expressed as exchange coupling constant $J$, and the bridging ligands to correlate the structural and magnetic properties. The present study has two goals: first, to evaluate the exchange coupling cons$\operatorname{tants} J$ for two selected model dimers using density functional 
theory (DFT) combined with the broken-symmetry (BS) approach, and second, to investigate the magnetic coupling interaction mechanism through the spin densities and molecular orbital considerations.

\section{Computational Methodology}

Description of the structure. The crystal structure of $[\mathrm{Cu}$ $(\mathrm{NCO})_{2}($ pyz) $]$ (pyz=pyrazine) (1) consists of parallel chains of the $\mathrm{Cu}^{2+}$ ions bridged by bis-monodentate pyrazine ligands organized along the $b$-axis, as shown in Figure 1. The cyanate anions, which are quasi-linear $\left(\mathrm{N}-\mathrm{C}-\mathrm{O}, 177.8^{\circ}\right)$, lie in the $a c$ plane and bridge the $\mathrm{Cu}$-pyz-Cu chains together to afford a $2 \mathrm{D}$ rectangular grid. The coordination sphere of each $\mathrm{Cu}^{2+}$ ion exhibits a Jahn-Teller elongated octahedral arrangement to give typical 4 short and 2 long bond geometry: the basal plane is formed by four nitrogen atoms, two from end-on cyanato bridges and the other two from two pyrazine bridges. The axial positions are filled by the other two end-on cyanato bridges. Thus, 1 can be described as a 2D grid-like network consisting of $\mathrm{Cu}$ pyz-Cu chains which are connected via four end-on cyanato bridges.

The $\mathrm{Cu}-\mathrm{N}$ distances for the basal plane are $\mathrm{Cu}-\mathrm{N}($ cyanato $)=$ $1.958 \AA, \mathrm{Cu}-\mathrm{N}($ pyz $)=2.061 \AA$; the axial $\mathrm{Cu}-\mathrm{N}$ bonds are $\mathrm{Cu}-\mathrm{N}$ $($ cyanato $)=2.618 \AA$, significantly longer than the $\mathrm{Cu}-\mathrm{N}$ bond length occupying the basal position. The plane of the pyrazine ring is tilted out of the basal coordination plane of the copper atoms by approximately $50^{\circ}$. The axial $\mathrm{N}-\mathrm{Cu}-\mathrm{N}$ bond angle is $180^{\circ}$. The $\mathrm{Cu}-\mathrm{N}$ (cyanato)-Cu and $\mathrm{N}$ (cyanato)-Cu-N(pyz) bond

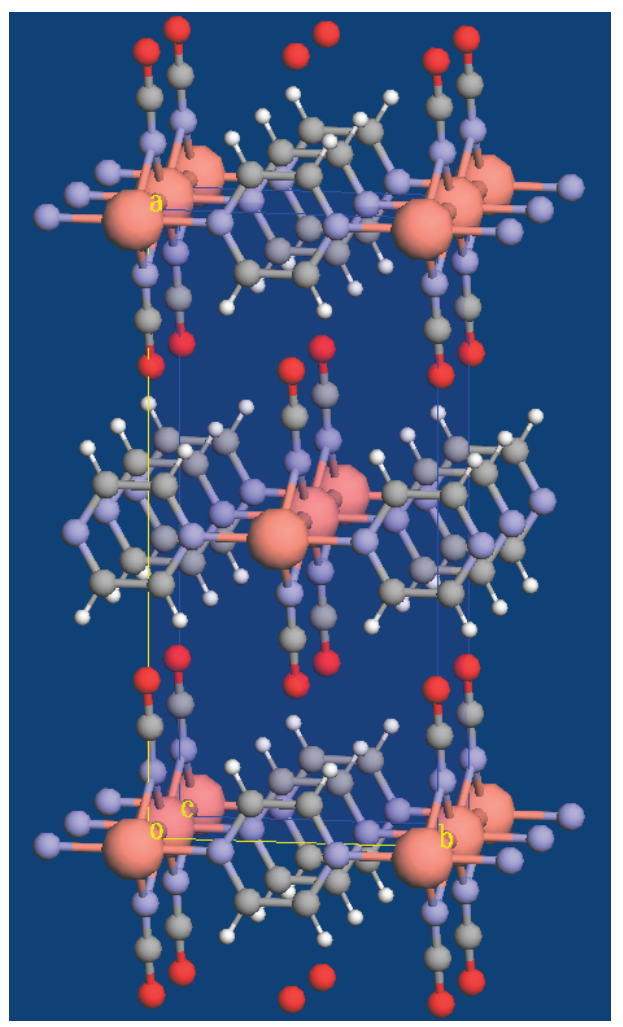

Figure 1. Crystal structure of $\mathrm{Cu}(\mathrm{NCO})_{2}(\mathrm{pyz})$ viewed along the [001] direction. angles are $96.6^{\circ}$ and $90.0^{\circ}$, respectively. The adjacent $\mathrm{Cu}-\mathrm{Cu}$ distances along the chain of $\left[\mathrm{Cu}(\mathrm{NCO})_{2}\right]$ and $\mathrm{Cu}$-pyz units are 3.444 and $6.894 \AA$, respectively. The shortest internetwork $\mathrm{Cu}-\mathrm{Cu}$ separation is $8.176 \AA$, and consequently, no internetwork interactions are expected. All bond distances and angles are almost comparable to those found in $\left[\mathrm{Cu}\left(\mathrm{N}_{3}\right)_{2}(\mathrm{pyz})\right]_{\mathrm{n}}{ }^{9}$

Evaluation of exchange coupling constants. To analyze the exchange pathways which are responsible for the ferro- and antiferromagnetic interactions observed in $\mathbf{1}$, we have performed DFT ${ }^{10}$ calculations on the model systems shown in I and II (Figure 2), where the terminal pyrazine and cyanato nitrogen atoms have been replaced by ammonia groups. The bond lengths and bond angles of these species were fixed at the values taken from the crystal structure determination. A spin dimer II along the $b$-axis is obtained from two spin monomers bridged by a pyrazine molecule, while the other spin dimer I along the $c$-axis is obtained from two spin monomers sharing two cyanate anions. Once this was done, the complete dimeric structures were used in the calculations to estimate the values of the exchange coupling constant $J$.

Two separate calculations were done, one for the triplet and another for a broken-symmetry (BS) singlet state. The exchange interaction between the two magnetic centers is derived from the spin coupling Hamiltonian given in eq 1 , where $S_{1}$ and $S_{2}$ are the spin operators for the two respective metal centers. ${ }^{11}$

$$
\mathrm{H}=-J S_{I} \cdot S_{2}
$$

The singlet-triplet energy gap $(J)$ was evaluated from the

(a)

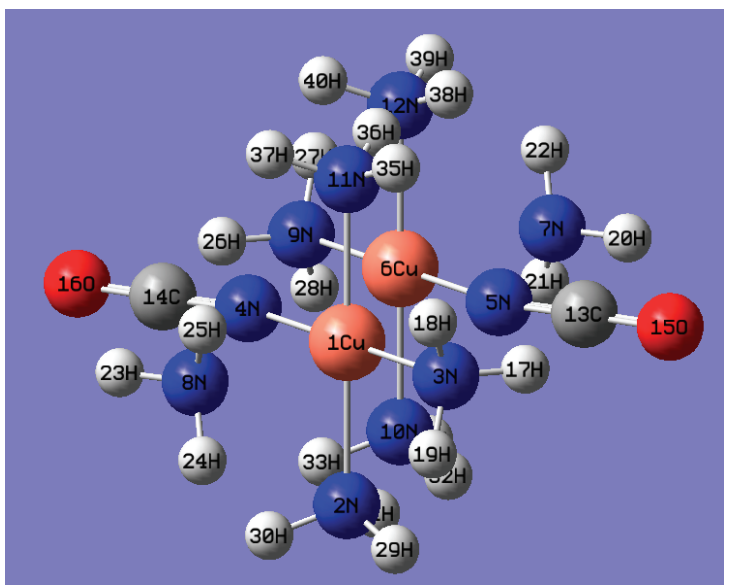

(b)

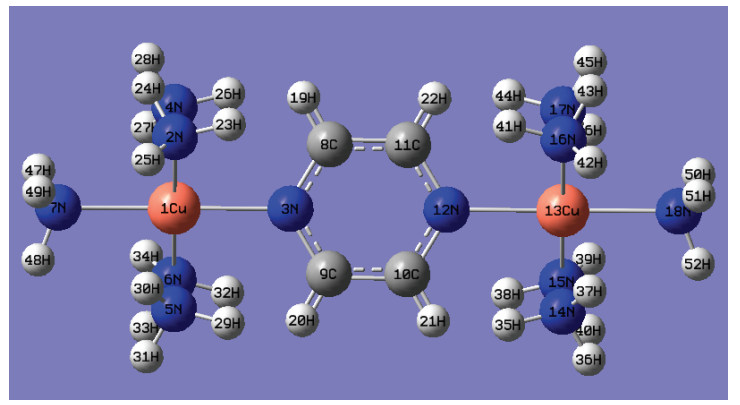

Figure 2. Binuclear molecular models $\mathbf{I}\left[\mathrm{Cu}_{2}(\mathrm{NCO})_{2}\left(\mathrm{NH}_{3}\right)_{8}\right]^{2+}$ (a) and II $\left[\mathrm{Cu}_{2}(\right.$ pyz $\left.\left.)\left(\mathrm{NH}_{3}\right)_{10}\right)\right]^{4+}$ (b) used for the DFT calculations. 
Table 1. Total energies and exchange coupling constants calculated for model dicopper(II) complexes I and II shown in Figure 2, using B3LYP method with several basis sets ${ }^{a}$

\begin{tabular}{|c|c|c|c|c|}
\hline dimer & basis set & $E_{\mathrm{BS}}(\mathrm{au})$ & $E_{\mathrm{HS}}(\mathrm{au})$ & $J\left(\mathrm{~cm}^{-1}\right)$ \\
\hline \multirow{2}{*}{ I } & TZVP/SVP & -4068.8684430 & -4068.8684487 & 1.25 \\
\hline & $\mathrm{TZVP} / 6-31 \mathrm{G}^{*}$ & -4069.4003831 & -4069.4003866 & 0.77 \\
\hline \multirow{2}{*}{ II } & TZVP/SVP & -4109.1694552 & -4109.1694412 & -3.07 \\
\hline & $\mathrm{TZVP} / 6-31 \mathrm{G}^{*}$ & -4109.7347936 & -4109.7347804 & -2.90 \\
\hline
\end{tabular}

${ }^{a}$ TZVP for $\mathrm{Cu}(\mathrm{II}), \mathrm{SVP}$ and $6-31 \mathrm{G}^{*}$ for the remaining atoms.

calculated energies of the triplet $\left(E_{\mathrm{HS}}\right)$ and $\mathrm{BS}$ singlet $\left(E_{\mathrm{BS}}\right)$ spin states through eq 2 ,

$$
J=\frac{2\left[E_{\mathrm{BS}}-E_{\mathrm{HS}}\right]}{S(S+1)}
$$

where $S$ is the total spin for the high-spin (HS) state. ${ }^{12}$ Therefore, a positive (negative) value of $J$ indicates ferromagnetic (antiferromagnetic) coupling with a triplet (BS singlet) ground state.

The hybrid functional $\mathrm{B} 3 \mathrm{LYP}^{13}$ with several basis sets $\left(\mathrm{SVP},{ }^{14}\right.$ TZVP, ${ }^{14} 6-31 \mathrm{G}^{* 15}$ ) as implemented in Gaussian $03^{16}$ was used for the calculations of the exchange coupling constant of model dimers I and II. These results are given in Table 1. The results indicate that the B3LYP method leads to acceptable results with negligible differences between the basis sets TZVP/SVP and TZVP/6-31G*. Larger basis sets are needed for the metal centers. Very large basis sets such as TZVP are unnecessary for the majority of the ligand system, and smaller basis sets already give a relatively accurate description of exchange-coupled systems. In order to reduce the computational cost for these calculations, a combination of the TZVP basis for the transition metal centers with the smaller 6-31G* basis set for the ligand backbone was used to increase the performance. The resulting $J$ values are very similar to those with the SVP basis set, and this combination might be therefore used for the applications to larger spin clusters.

\section{Results and Discussion}

Evaluation of $\boldsymbol{J}$ for each model spin dimer. The calculated $J$ values for model dimers I and II with different basis sets are listed in Table 1. These results are in good agreement with the observed magnetic interactions. Judging by the $J$ values in Table 1, it is clearly shown that the basis set TZVP (for the metal centers) $/ 6-31 \mathrm{G}^{*}$ (for the remaining atoms) can provide fairly good results in the treatment of the magnetic systems with enough accuracy and reliability, as reported by another group. ${ }^{17}$ When we compare this method with the popular split basis set TZVP/SVP, the accuracy of these two methods is similar but the computational time is reduced by almost a factor of 2 with the TZVP/6-31G*.

Orbital analysis of the exchange pathways in $\mathrm{Cu}(\mathrm{NCO})_{2}$ (pyz). Keeping in mind the 2D structure of [Cu(NCO $)_{2}($ pyz $\left.)\right]$ (1), where the $\mathrm{Cu}$-pyz-Cu chains are connected by end-on cyanato bridges, the exchange parameter $J$ through the pyrazine
Table 2. SOMO energy gap $\Delta \mathrm{e}$ (in $\mathrm{meV}$ ) in the high-spin state for the two model dimers of $\left[\mathrm{Cu}(\mathrm{NCO})_{2}(\mathrm{pyz})\right]$ obtained by B3LYP with TZVP/ SVP basis set

\begin{tabular}{ccc}
\hline magnetic orbital & along $c($ I $)$ & along $b($ II) \\
\hline$x^{2}-y^{2}$ & 54 & 106 \\
\hline
\end{tabular}

or end-on cyanato bridges was used to analyze its magnetic behavior. The calculated $J$ values for model dimers I and II in Figure 2 are $+1.25(0.77)$ and $-3.07(-2.90) \mathrm{cm}^{-1}$, respectively (Table 1). The DFT/B3LYP calculations well reproduced the experimental magnetic interactions in $\mathbf{1}$. The facts that the magnetic couplings through pyrazine and end-on cyanato bridges are relatively weak and that they are of different natures are very interesting. Focusing on the two models, it is clear that the $\mathrm{N}-\mathrm{C}-\mathrm{C}-\mathrm{N}$ skeleton of the pyrazine bridge is more efficient than the end-on cyanato bridge in mediating exchange interactions between the copper(II) ions. Electronic structure calculations on the two bridging ligands provide an orbital explanation for this finding.

The interaction of HOMOs of the bridging ligands of appropriate symmetry with the in phase and out of phase combinations of the metal-centered magnetic orbitals results in two singly occupied molecular orbitals (SOMOs) for model dimers I and II, which determine the magnetic behaviors of the molecular systems. According to the molecular orbital model by Hay et al..${ }^{6}$ the value of $J$ in a copper(II) dimer can be expressed by the sum of a ferromagnetic $\left(J_{\mathrm{F}}>0\right)$ and an antiferromagnetic $\left(J_{\mathrm{AF}}<0\right)$ contributions. Only when $J_{\mathrm{AF}}$ contribution is null or negligible the ferromagnetic behavior, $J_{\mathrm{F}}$, is predominant. The antiferromagnetic contribution can be analyzed as a function of the square of the energy gap in the pairs of SOMOs derived from magnetic orbitals. Although two-electron integrals appear in this expression, it is generally accepted that, within a family of related compounds, the two-electron terms are nearly constant and the variations in the values of $J$ are roughly related to the variations of the square of the energy gap between the SOMOs. ${ }^{18}$

For copper(II) ions in axially elongated octahedral environments, the magnetic orbital that is the molecular orbital which describes the unpaired electron is mainly localized in the equatorial plane and it is of the $x^{2}-y^{2}$ type (the $x$ and $y$ axes being roughly defined by the short copper to ligand-nitrogen bonds). Thus, for each spin dimer of $\mathbf{1}$, two $x^{2}-y^{2}$ levels split and hence give the energy gap $(\Delta \mathrm{e})$ between the symmetric $(\mathrm{S})$ and antisymmetric (A) combinations of the $x^{2}-y^{2}$ orbitals (Figures 3 and 4). In this sense, the antiferromagnetic contribution to $J$ should be proportional to the $\left[(\Delta \mathrm{e})^{2}\right]\left(x^{2}-y^{2}\right)$. According to our B3LYP/TZVP/SVP calculations, the energy splittings of the SOMOs for model dimers I and II are 0.054 and $0.106 \mathrm{eV}$, respectively. The criterion of Hay et $\mathrm{al}^{6}{ }^{6}$ is applicable to these dicopper(II) complexes. That is, if the energy splittings of SOMOs for dicopper(II) complexes lie within a range $0.1-0.2 \mathrm{eV}$, an antiferromagnetic coupling should be preferred. From Table 2, we can see that the energy splitting of the corresponding SOMOs in the triplet state for pyrazine-bridged spin dimer (along $b$ ) is larger than that for the cyanato-bridged one (along $c$ ). 

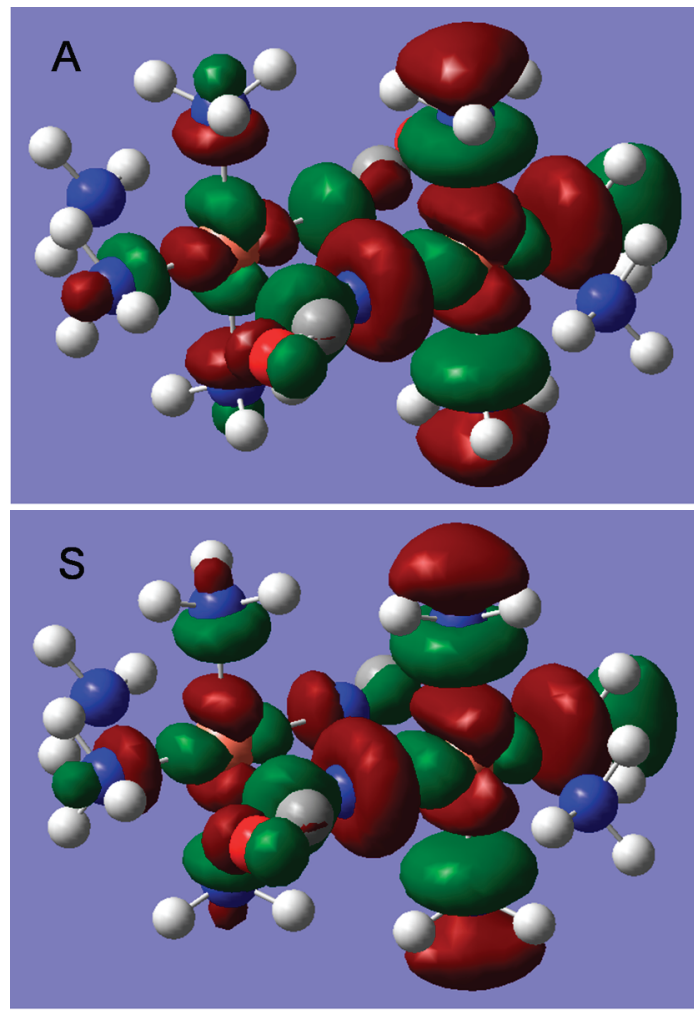

Figure 3. SOMOs in the triplet state for the cyanato-bridged spin dimer I and their corresponding energies (A: $-9.056 \mathrm{eV}, \mathrm{S}:-9.110 \mathrm{eV}$ ).
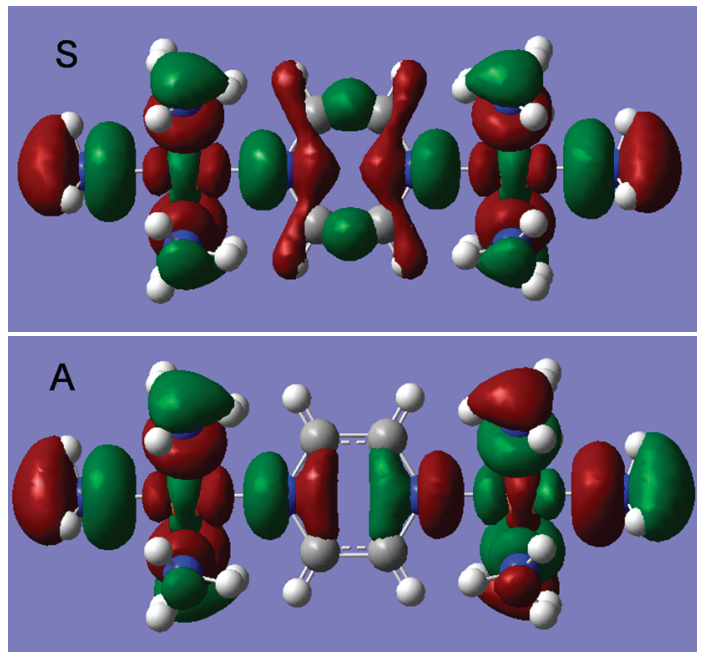

Figure 4. SOMOs in the triplet state for the pyrazine-bridged spin dimer II and their corresponding energies (S: $-18.686 \mathrm{eV}, \mathrm{A}:-18.792 \mathrm{eV}$ ).

The large energy splitting of SOMOs in model II suggests that the superexchange interaction should be responsible for its weak antiferromagnetic coupling. A smaller antiferromagnetic contribution is expected for model I, as compared to model II, due to its smaller energy splitting of SOMOs. Therefore, the calculated value of $J$ for $I$ is slightly positive in contrast to the negative $J$ value for II (see Table 1).

The molecular orbital analysis reveals that the reduction of the antiferromagnetic contribution in $\mathbf{I}$, as compared to that in
II, is responsible for the occurrence of a ferromagnetic exchange pathway in $\mathbf{I}$. The fact that the magnetic interaction within the dimeric unit with end-on cyanato bridges is weakly ferromagnetic can be easily understood on the basis of simple magnetic orbital considerations. One copper-centered magnetic orbital is parallel with that centered on the other $\mathrm{Cu}$ atom, which is separated from the former by $3.44 \AA$, as shown in Figure 3. In addition, these atoms are shifted in such a way that the bridging cyanato $\mathrm{N}$ atom occupies one equatorial position at a $\mathrm{Cu}$ atom and the apical site at the other one. Along the $c$-axis, the equatorial-axial coordination of the cyanato bridge and the long axial $\mathrm{Cu}-\mathrm{N}$ bond distance lead to a very poor overlap of the $\pi$ orbitals of the bridging entities with the magnetic orbitals of the metal atoms. In other words, the bridging cyanate anion does not play a role in the formation of an efficient overlap interaction pathway. The energy separation of the pair of SOMOs of the dimer is very small, $0.054 \mathrm{eV}$. As a consequence, the antiferromagnetic component of $J$ should be very small and the weak $J_{\mathrm{F}}$ is dominant, giving a net weak ferromagnetic character. A clear correlation between the energy gap $\Delta \mathrm{e}$ and $J$ indicates that the smaller the gap is, the more is a ferromagnetic coupling favored. The results of these calculations show that the cyanato bridge acts in a very similar manner to the azido system: the essentially nonbonding $\pi$ MOs of the cyanate are the most important pathway of superexchange, but a very weak contribution from the $\sigma$-like pathway to the antiferromagnetic component $J_{\mathrm{AF}}$ is found. The origin of the ferromagnetic coupling between the two copper-centered $x^{2}-y^{2}$ magnetic orbitals through this bridging ligand can thus be rationalized as being due to the quasi-orthogonality of the magnetic orbitals of the two mononuclear fragments. This weak ferromagnetic interaction is responsible for the increase of the $\chi_{\mathrm{M}} T$ versus $T$ curve upon cooling to $c a .50 \mathrm{~K}$.

In contrast, as observed from the $\Delta \mathrm{e}$ values of Table 2 , the spin exchange interactions of $\mathbf{1}$ are stronger along the $b$-axis than along the $c$-axis. The rapid decrease of $\chi_{M} T$ values observed on the magnetic susceptibility below $50 \mathrm{~K}$ probably indicates that antiferromagnetic ordering occurs within the $\mathrm{Cu}-\mathrm{pyz}-\mathrm{Cu}$ chains along the $b$-axis. The observed antiferromagnetic interactions can be explained in terms of the orientation of the $\mathrm{Cu}$ $x^{2}-y^{2}$ magnetic orbital with-respect-to the pyrazine lone-pair orbitals. In the structure, the $\mathrm{Cu}-\mathrm{N}(\mathrm{pyz})$ bond lies in the plane of the copper magnetic orbital and the angle of $\mathrm{Cu}-\mathrm{N} \cdots \mathrm{N}$ is $180^{\circ}$. This means that one lobe of the $x^{2}-y^{2}$ orbital pointing along the $\mathrm{Cu}-\mathrm{N}(\mathrm{pyz})$ bond can overlap more efficiently with the $\sigma$ lonepair orbitals of the nitrogen atoms in the bridging pyrazine molecule, and therefore the $\sigma$ exchange pathway can be formed along the $b$-axis (see Figure 4). The geometry thus favors an antiferromagnetic superexchange coupling across the pyrazine ring. Even through the $\sigma$ pathway the antiferromagnetic interaction is weak. In order to examine the origin of this behavior, we need to consider the two lone-pair levels in pyrazine. The throughspace 1,4-interaction between the hybrid lone-pairs of nitrogen generates the two symmetry-adapted levels $n+$ and n-, of which the energy difference is expected to be small. However, the through-bond 1,2-interactions of the $\mathrm{n}+$ and $\mathrm{n}^{-}$orbitals with the $\mathrm{C}-\mathrm{C} \sigma$ and $\sigma^{*}$ orbitals lead to a large splitting between the $\mathrm{n}+$ and $\mathrm{n}^{-}$levels. These lone-pair orbitals include small contri- 
butions from the carbon atoms. The two $\mathrm{Cu} x^{2}-y^{2}$ orbitals mix in an antibonding fashion (out of phase) with the two symmetryadapted $\sigma$ lone-pair orbitals of the pyrazine which differ by a large amount in energy, leading to a substantial energy splitting between the two SOMOs of the dimer. The symmetric combination of $\mathrm{Cu} x^{2}-y^{2}$ orbitals lies higher in energy than the antisymmetric one because of the greater interaction of $x^{2}-y^{2}$ with the $\mathrm{n}+$ orbital relative to the the $\mathrm{n}-$ orbital of pyrazine. Since the overlap of the two $\mathrm{Cu} x^{2}-y^{2}$ orbitals does not involve the $\pi$ orbitals of the pyrazine bridge by reason of symmetry constraints, the energy splitting $(0.106 \mathrm{eV})$ between the two SOMOs is not too large, and consequently weak antiferromagnetic coupling through the pyrazine is predicted. Another reason for this could be partly due to the contribution of nitrogen lone-pair orbitals with minor contributions of the $2 p$ orbitals of the $\mathrm{C}$-ring atoms for the pyrazine and the large $\mathrm{Cu}-\mathrm{Cu}$ distance separated by more than $6.7 \AA$. The $\mathrm{Cu}-\mathrm{N}(\mathrm{pyz})$ bond $(2.06 \AA)$ and the intradimer $\mathrm{Cu} \cdots \mathrm{Cu}$ distance $(6.89 \AA)$ are particularly long in this compound. In the majority of $\mathrm{Cu}$ (II) complexes with pyrazine-type bridging ligands studied so far the magnetic interaction is weak and of antiferromagnetic character. ${ }^{19}$ The available data ${ }^{20}$ thus suggest that the structural distortion favoring magnetic exchange through the $d \sigma($ copper)-p $\pi($ pyz) interaction and the presence of short (less than $2.00 \AA$ ) $\mathrm{Cu}-\mathrm{N}($ pyz) bonds are necessary for appreciable magnetic coupling through pyrazine bridge to occur.

Spin density distribution. In addition to the exchange coupling constant, it is interesting to study the spin density distribution in this compound. Mulliken atomic spin densities obtained from our calculations for models I and II are presented in Table 3. The positive and negative signs indicate $\alpha$ and $\beta$ spin states, respectively. In the triplet ground state of $\mathbf{I}$, the spin population on $\mathrm{Cu} 1$ is 0.633 , and those on the directly coordinated basal atoms $(\mathrm{N} 2, \mathrm{~N} 3, \mathrm{~N} 4$, and N11) have the same sign

Table 3. Mulliken spin densities calculated from B3LYP with TZVP/ SVP basis set for models I and II in the triplet and BS singlet ground states, respectively

\begin{tabular}{cccr}
\hline model I & \multicolumn{3}{c}{ model II } \\
\hline $\mathrm{Cu} 1$ & 0.633 & $\mathrm{Cu} 1$ & 0.614 \\
$\mathrm{~N} 2$ & 0.094 & $\mathrm{~N} 2$ & 0.106 \\
$\mathrm{~N} 3$ & 0.099 & $\mathrm{~N} 3$ & 0.072 \\
$\mathrm{~N} 4$ & 0.079 & $\mathrm{~N} 4$ & 0.002 \\
$\mathrm{~N} 5$ & 0.079 & $\mathrm{~N} 5$ & 0.002 \\
$\mathrm{Cu} 6$ & 0.633 & $\mathrm{~N} 6$ & 0.107 \\
$\mathrm{~N} 7$ & 0.001 & $\mathrm{~N} 7$ & 0.124 \\
$\mathrm{~N} 8$ & 0.000 & $\mathrm{C} 8$ & -0.013 \\
$\mathrm{~N} 9$ & 0.100 & $\mathrm{C} 9$ & -0.013 \\
$\mathrm{~N} 10$ & 0.093 & $\mathrm{C} 10$ & 0.013 \\
$\mathrm{~N} 11$ & 0.094 & $\mathrm{C} 11$ & 0.013 \\
$\mathrm{~N} 12$ & 0.093 & $\mathrm{~N} 12$ & -0.072 \\
$\mathrm{C} 13$ & 0.002 & $\mathrm{Cu} 13$ & -0.614 \\
$\mathrm{C} 14$ & 0.002 & $\mathrm{~N} 14$ & -0.002 \\
$\mathrm{O} 15$ & 0.008 & $\mathrm{~N} 15$ & -0.107 \\
$\mathrm{O} 16$ & 0.008 & $\mathrm{~N} 16$ & -0.106 \\
& & $\mathrm{~N} 17$ & -0.002 \\
& & $\mathrm{~N} 18$ & -0.124 \\
\hline
\end{tabular}

as that on $\mathrm{Cu} 1$, corresponding to the spin delocalization from the $\mathrm{Cu}$ (II) spin center. Likewise, the spin population on $\mathrm{Cu} 6$ is 0.633 , and those on the directly coordinated basal atoms (N5, N9, N10, and N12) also have the same sign as that on Cu6. Meanwhile, in the BS singlet state of II, the $\mathrm{Cul}$ and the directed coordinated basal atoms (N2, N3, N6, and N7) have the positive density, and the $\mathrm{Cu} 13$ and the directed coordinated basal atoms (N12, N15, N16, and N18) have the negaitive density, demonstrating the spin delocalization from $\mathrm{Cu}$ (II) to the ligands for the $\mathrm{Cu}$ centered fragment. The sign alternation of the spin density is found on adjacent carbon atoms of the bridging pyrazine ligand. Obviously, the spin density distribution on pyrazine can be rationalized by the spin polarization mechanism. ${ }^{21}$

Figures $5 \mathrm{a}$ and $5 \mathrm{~b}$ illustrate the spin densities in the ground states calculated for models I and II by B3LYP with TZVP/ SVP basis set, respectively. The regions of $\alpha$ and $\beta$ spin densities are shown in blue and green colors, respectively, and the cut-off threshold is set to be 0.001 . The spin density distribution around the metal center resembles an $x^{2}-y^{2}$ orbital with a small contribution of $z^{2}$. From Figure 5 and Table 3, we find that $\mathrm{Cu}$ and the coordinated nitrogen atoms carry spin densities with the same sign for both models. These spin structures can be interpreted in terms of the spin delocalization effect. This situation shows a sharp contrast to that of the bridging pyrazine ligand, in which the spin density alternates throughout the $\mathrm{N}-\mathrm{C}-\mathrm{C}-\mathrm{N}$ path of the ring.

\section{Concluding Remarks}

We have employed a DFT broken-symmetry approach to calculate the exchange coupling constants for the models I and

(a)

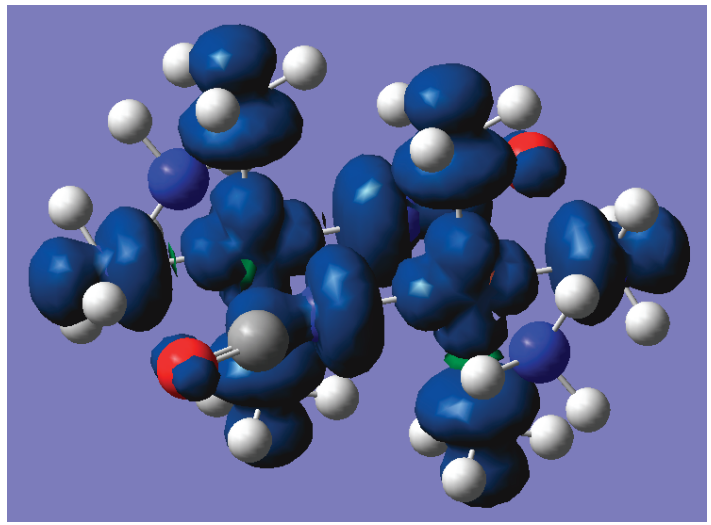

(b)

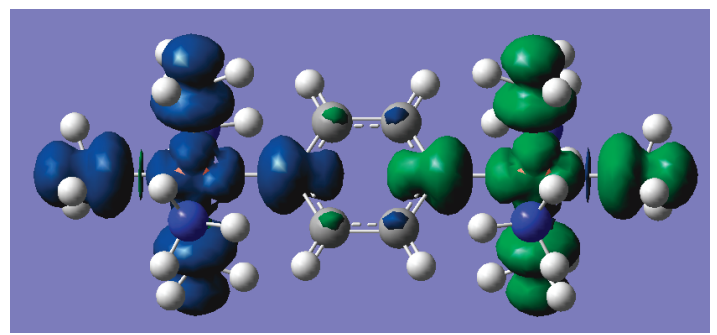

Figure 5. Calculated spin density distribution for the ground state of models I (a) and II (b) with the surface threshold level of 0.001 ( $\alpha$ : blue, $\beta$ : green). 
II with pyrazine or cyanato-bridged $\mathrm{Cu}$ (II) dimeric fragments in $\left[\mathrm{Cu}(\mathrm{NCO})_{2}(\mathrm{pyz})\right]$. The calculated $J$ values show very weak ferro- (through EO cyanato bridges, I) and antiferromagnetic (through pyrazine bridges, II) interactions, in good agreement with experimental results. We have clarified that the pyrazine bridge works as an antiferromagnetic coupler in $\mathbf{1}$ and that the origin of the magnetic coupling is a superexchange through a $\sigma$-overlap interaction pathway formed between the $\mathrm{Cu} x^{2}-y^{2}$ orbitals and the nitrogen lone-pair orbitals of pyrazine along $\mathrm{Cu}-\mathrm{N} \cdots \mathrm{N}-\mathrm{Cu}$ linkage. On the other hand, the HOMOs of the basal-apical NCO bridge in I do not play a role in the formation of an efficient overlap interaction pathway. The energy separation in the pair of SOMOs of the dimer is calculated to be very small $(0.054 \mathrm{eV})$. This result is consistent with the occurrence of weakly ferromagnetic properties in $\mathbf{1}$. In order to tackle the problem of an infinite chain calculation we adopted a simplified model dimer preserving all structural features of the repetitive unit in the polymeric real system. The successful results suggest that this methodology could be a useful tool in the evaluation of exchange coupling constants for 1D infinite copper(II) systems at a lower computational cost.

Acknowledgments. This work was supported by the Kyungsung University Research Grant in 2010.

\section{References}

1. (a) Carlin, R. L.; Van Duyneveldt, A. J. Magnetic Properties of Transition Metal Compounds; Springer-Verlag: New York, 1977. (b) Carlin, R. L. Magnetochemistry; Springer-Verlag: Berlin-Heidelberg, 1986. (c) Kahn, O. Molecular Magnetism; VCH: New York, 1993. (d) Miller, J. S.; Drillon, M. Magnetism: Molecules to Materials; Wiley-VCH: Weinheim, 2002-2005; Vol. I-V. (e) Thompson, L. K. Coord. Chem. Rev. 2005, 249, 2549-2730.

2. Entley, W. R.; Girolami, G. S. Science 1995, $268,397$.

3. (a) Escuer, A.; Aromi, G. Eur. J. Inorg. Chem. 2006, 4721. (b) Ribas, J.; Escuer, A.; Monfort, M.; Vicente, R.; Cortes, R.; Lezama, L.; Rojo, T. Coord. Chem. Rev. 1999, 195, 1027. (c) Karmakar, T. K.; Ghosh, B. K.; Usman, A.; Fun, H. K.; Riviere, E.; Mallah, T.; Aromi, G.; Chandra, S. K. Inorg. Chem. 2005, 44, 2391. (d) Tandon, S. S.; Thompson, L. K.; Manuel, M. E.; Bridson, J. N. Inorg. Chem. 1994, 33, 5555. (e) Ako, A. M.; Hewitt, I. J.; Mereacre, V.; Clerac, R.; Wernsdorfer, W.; Anson, C. E.; Powell, A. K. Angew. Chem., Int. Ed. 2006, 45, 4926. (f) Aromi, G.; Parsons, S.; Wernsdorfer, W.; Brechin, E. K.; McInnes, E. J. L. Chem. Commun. 2005, 5038. (g) Bell, A.; Aromi, G.; Teat, S. J.; Wernsdorfer, W.; Winpenny, R. E. P. Chem. Commun. 2005, 2808. (h) Boudalis, A. K.; Donnadieu, B.; Nastopoulos, V.; Modesto Clemente-Juan, J.; Mari, A.; Sanakis, Y.; Tuchagues, J.-P.; Perlepes, S. P. Angew. Chem., Int. Ed. 2004, 43, 2266. (i) Murugesu, M.; Habrych, M.; Wernsdorfer, W.; Abboud, K. A.; Christou, G. J. Am. Chem. Soc. 2004, 126, 4766. (j) Abu-Youssef, M. A. M.; Escuer, A.; Goher, M. A. S.; Mautner, F. A.; Reiss, G. J.; Vicente, R. Angew. Chem., Int. Ed. 2000, 39, 1624.

4. (a) Arriortua, M. I.; Cortes, R.; Mesa, J. L.; Lezama, L.; Rojo, T.; Villeneuve, G. Transition Met. Chem. 1988, 13, 371. (b) ClementeJuan, J. M.; Mackiewicz, C.; Verelst, M.; Dahan, F.; Bousseksou, A.; Sanakis, Y.; Tuchagues, J. P. Inorg. Chem. 2002, 41, 1478. (c) Talukder, P.; Datta, A.; Mitra, S.; Rosair, G.; El Fallah, M. S.; Ribas, J. Dalton Trans. 2004, 4161. (d) Carranza, J.; Sletten, J.; Lloret, F.; Julve, M. J. Mol. Struct. 2008, 890, 31. (e) Youngme, S.; Phatchimkun, J.; Suksangpanya, U.; Pakawatchai, C.; van Albada, G. A.; Reedijk, J. Inorg. Chem. Commun. 2005, 8, 882. (f) Grove,
H.; Julve, M.; Lloret, F.; Kruger, P. E.; Törnroos, K. W.; Sletten, J. Inorg. Chim. Acta 2001, 325, 115. (g) Escuer, A.; Font-Bardia, M.; Penalba, E.; Solans, X.; Vicente, R. Inorg. Chim. Acta 1999, 286, 189. (h) Diaz, C.; Ribas, J.; Salah El Fallah, M.; Solans, X.; Font-Bardia, M. Inorg. Chim. Acta 2001, 312, 1. (i) Chen, Z.-N.; Zhang, H.-X.; Yu, H.-B.; Zheng, K.-C.; Cai, H.; Kang, B.-S. J. Chem. Soc. Dalton Trans. 1998, 1133.

5. (a) Santoro, A.; Mighell, A. D.; Reimann, C. W. Acta Crystallogr. Sect. B: Struct. Crystallogr. Cryst. Chem.1970, 26, 979. (b) Carreck, P. W.; Goldstein, M.; MacPartlin, E. M.; Unsworth, W. D. J. Chem. Soc. Chem. Commun. 1971, 1634. (c) Darriet, J.; Haddad, M. S.; Duester, E. N.; Hendrickson, D. N. Inorg. Chem. 1979, 18, 2679. (d) Real, J. A.; Munno, G. D.; Munoz, M. C.; Julve, M. Inorg. Chem. 1991, 30, 2701. (e) Bordallo, H. N.; Chapon, L.; Manson, J. L.; Ling, C. D.; Qualls, J. S.; Hall, D.; Argyriou, D. Polyhedron 2003, 22, 2045.

6. Hay, P. J.; Thibeault, J. C.; Hoffman, R. J. Am. Chem. Soc. 1975, 97, 4884.

7. (a) Manson, J. L.; Huang, Q. Z.; Lynn, J. W.; Koo, H. J.; Whangbo, M. H.; Bateman, R.; Otsuka, T.; Wada, N.; Argyriou, D. N.; Miller, J. S. J. Am. Chem. Soc. 2001, 13, 162. (b) Sun, H.-L.; Ma, B.-Q.; Gao, S.; Su, G. Chem. Commun. 2001, 24, 2586.

8. Wriedt, M.; Näther, C. Z. Anorg. Allg. Chem. 2009, 635, 1115.

9. Dong, W.; Ouyang, Y.; Liao, D.-Z.; Yan, S.-P.; Cheng, P.; Jiang, Z.-H. Inorg. Chim. Acta 2006, 359, 3363.

10. Parr, R. G.; Yang, W. Density Functional Theory of Atoms and Molecules; Oxford University Press: New York, 1989.

11. Ciofini, I.; Daul, C. A. Coord. Chem. Rev. 2003, 238-239, 187.

12. (a) Noodleman, L. J. Chem. Phys. 1981, 74, 5737. (b) Noodleman, L.; Davidson, E. R. Chem. Phys. 1986, 109, 131. (c) Ruiz, E.; Cano, J.; Alvarez, S.; Alemany, P. J. Comput. Chem. 1999, 20, 1391.

13. (a) Becke, A. D. J. Chem. Phys. 1993, 98, 5648. (b) Becke, A. D. Phys. Rev. A 1988, 38, 3098. (c) Lee, C.; Yang, W.; Parr, R. G. Phys. Rev. B 1988, 37, 785.

14. (a) Schafer, A.; Horn, H.; Ahlrichs, R. J. Chem. Phys. 1992, 97 , 2571. (b) Schafer, A.; Huber, C.; Ahlrichs, R. J. Chem. Phys. 1994, 100,5829 .

15. (a) Ditchfield, R.; Hehre, W. J.; Pople, J. A. J. Chem. Phys. 1971, 54, 724. (b) Hehre, W. J.; Ditchfield, R.; Pople, J. A. J. Chem. Phys. 1972, 56, 2257. (c) Hariharan, P. C.; Pople, J. A. Mol. Phys. 1974, 27, 209. (d) Gordon, M. S. Chem. Phys. Lett. 1980, 76, 163. (e) Hariharan, P. C.; Pople, J. A. J. Chem. Phys. 1973, 82, 213. (f) Blaudeau, J.-P.; McGrath, M. P.; Curtiss, L. A.; Radom, L. J. Chem. Phys. 1997, 107, 5016. (g) Francl, M. M.; Pietro, W. J.; Hehre, W. J.; Binkley, J. S.; DeFrees, D. J.; Pople, J. A.; Gordon, M. S. J. Chem. Phys. 1982, 77, 3654 (h) Binning, R. C., Jr.; Curtiss, L. A. J. Comput. Chem. 1990, 11, 1206. (i) Rassolov, V. A.; Pople, J. A.; Ratner, M. A.; Windus, T. L. J. Chem. Phys. 1998, 109, 1223. (j) Rassolov, V. A.; Ratner, M. A.; Pople, J. A.; Redfern, P. C.; Curtiss, L. A. J. Comput. Chem. 2001, 22, 976.

16. Frisch, M. J.; Trucks, G. W.; Schlegel, H. B.; Scuseria, G. E.; Robb, M. A.; Cheeseman, J. R.; Montgomery, J. A., Jr.; Vreven, T.; Kudin, K. N.; Burant, J. C.; Millam, J. M.; Iyengar, S. S.; Tomasi, J.; Barone, V.; Mennucci, B.; Cossi, M.; Scalmani, G.; Rega, N.; Petersson, G. A.; Nakatsuji, H.; Hada, M.; Ehara, M.; Toyota, K.; Fukuda, R.; Hasegawa, J.; Ishida, M.; Nakajima, T.; Honda, Y.; Kitao, O.; Nakai, H.; Klene, M.; Li, X.; Knox, J. E.; Hratchian, H. P.; Cross, J. B. Bakken, V.; Adamo, C.; Jaramillo, J.; Gomperts, R.; Stratmann, R. E.; Yazyev, O.; Austin, A.; Cammi, R.; Pomelli, C.; Ochterski, J. W.; Ayala, P. Y.; Morokuma, K.; Voth, G. A.; Salvador, P.; Dannenberg, J. J.; Zakrzewski, V. G.; Dapprich, S.; Daniels, A. D.; Strain, M. C.; Farkas, O.; Malick, D. K.; Rabuck, A. D.; Raghavachari, K.; Foresman, J. B.; Ortiz, J. V.; Cui, Q.; Baboul, A. G.; Clifford, S.; Cioslowski, J.; Stefanov, B. B.; Liu, G.; Liashenko, A.; Piskorz, P.; Komaromi, I.; Martin, R. L.; Fox, D. J.; Keith, T.; Al-Laham, M. A.; Peng, C. Y.; Nanayakkara, A.; Challacombe, M.; Gill, P. M. W.; Johnson, B.; Chen, W.; Wong, M. W.; Gonzalez, C.; Pople, J. A. Gaussian 03; Gaussian Inc.: Wallingford, CT, 2003. 
17. Comba, P.; Martin, B. J. Phys. Chem. A 2009, 113, 6751.

18. Alvarez, S.; Julve, M.; Verdaguer, M. Inorg. Chem. 1990, 29, 4500.

19. (a) Choi, J.; Woodward, J. D.; Musfeldt, J. L.; Landee, C. P.; Turnbull, M. M. Chem. Mater. 2003, 15, 2797. (b) Bordallo, H. N.; Chapon, L.; Manson, J. L.; Ling, C. D.; Qualls, J. S.; Hall, D.; Argyriou, D. N. Polyhedron 2003, 22, 2045. (c) Jones, B. R.; Varughese, P. A.; Olejniczak, I.; Pigos, J. M.; Musfeldt, J. L.; Landee, C. P.; Turnbull, M. M.; Carr, G. L. Chem. Mater. 2001, 13, 2127. (d) Haynes, J. S.; Rettig, S. J.; Sams, J. R.; Thompson, R. C.; Trotter, J. Can. J. Chem. 1987, 65, 420. (e) Suarez-Varela, J.; Colacio, E.; Romerosa, A.; Avila-Roson, J. C.; Hidalgo, M.
A.; Romero, J. Inorg. Chim. Acta 1994, 217, 39. (f) Grove, H.; Sletten, J.; Julve, M.; Lloret, F. J. Chem. Soc. Dalton Trans. 2000, 515. (g) Okubo, T.; Kondo, M.; Kitawaga, S. Synth. Met. 1997, 85, 1661.

20. (a) Graf, M.; Stoeckli-Evans, H.; Escuer, A.; Vicente, R. Inorg. Chim. Acta 1997, 257, 89. (b) Burkholder, E.; Golub, V.; O’Connor, C. J.; Zubieta, J. Inorg. Chem. 2003, 42, 6729. (c) Carranza, J.; Sletten, J.; Brennan, C.; Lloret, F.; Cano, J.; Julve, M. Dalton Trans. 2004, 3997.

21. Cano, J.; Ruiz, E.; Alvarez, S.; Verdaguer, M. Comments Inorg. Chem. 1998, 20, 27. 